\title{
VIOLÊNCIA OCUPACIONAL NA ATENÇÃO PRIMÁRIA E AS INTERFACES COM AS CONDIÇÕES E A ORGANIZAÇÃO DO TRABALHO
}

OCCUPATIONAL VIOLENCE IN PRIMARY CARE AND INTERFACES WITH WORK CONDITIONS AND ORGANIZATION

VIOLENCIA OCUPACIONAL EN LA ATENCIÓN PRIMARIA Y LAS INTERFACES CON LAS CONDICIONES Y LA ORGANIZACIÓN LABORAL

Anny Caroline dos Santos Olimpio

Roberta Cavalcante Muniz Lira 2

João Breno Cavalcante Costa ${ }^{3}$

Bianca Waylla Ribeiro Dionisio ${ }^{4}$

Adriana Vasconcelos Gomes 5

Como Citar:

Olímpio ACS, Lira RCM, Costa JBC, Dionisio BWR, Gomes AV. Violência ocupacional na Atenção Primária e as interfaces com as condições e a organização do trabalho. Sanare

(Sobral, Online). 2021; 20(2): 97-106.

Descritores: Violência no trabalho; Saúde do trabalhador; Atenção Primária à Saúde; Estratégia Saúde da Família; Condições de trabalho.

Descriptors: Violence at work; Worker's health; Primary Health Care; Family Health Strategy; Work conditions.

Descriptores: Violencia laboral; Salud del trabajador; Atención Primaria a la Salud; Estrategia Salud de la Familia; Condiciones de trabajo.

Submetido: $01 / 07 / 2021$

Aprovado:

$17 / 11 / 2021$

Autor(a) para Correspondência: Anny Caroline dos Santos Olímpio

Universidade Federal do Ceará Endereço: Rua Padre Eudes Fernandes, n. ${ }^{0} 258$, Coração de Jesus, Sobral, Ceará

CEP: 62043-215

E-mail: carolfloc@hotmail.com

Cert. de Redação Científica: Central das Revisões. Edição de texto: Karina Maria M. Machado. Revisão de provas: Texto definitivo validado pelos(as) autores (as).

\section{RESUMO}

0 estudo teve como objetivo analisar as evidências científicas que tratam sobre a violência ocupacional na saúde e as interfaces com as condições e organização do trabalho. Trata-se de uma revisão integrativa considerando artigos originais publicados em periódicos nacionais e internacionais. Foram cruzados os descritores "Violência no Trabalho", "Saúde do Trabalhador" e "Atenção Básica à Saúde", no período de 2008 a 2018. O tipo de violência ocupacional mais prevalente foi a física, seguida da violência psicológica; os pacientes foram os principais perpetradores, seguidos dos próprios colegas de trabalho. Investimentos nas condições e organização do trabalho reduzem as chances de violência no local de trabalho. Há necessidade de desenvolver estratégias organizacionais e políticas em geral para a proteção dos profissionais de saúde. A violência ocupacional é multicausal, com repercussões negativas no contexto laboral dos trabalhadores violentados. Dessa maneira, o maior envolvimento de gestores públicos e ações de planejamento estratégico podem auxiliar com mudanças desse paradigma.

1. Enfermeira. Mestranda em Saúde da Família. Universidade Federal do Ceará. E-mail: carolfloc@hotmail.com ORCID: https://orcid.org/0000-0002-3656-6001

2. Enfermeira. Doutora em Saúde Pública pela Universidade de São Paulo. Universidade Federal do Ceará. E-mail: beta_lira74@hotmail.com 0RCID: https://orcid.org/0000-0002-2163-4307

3. Enfermeiro. Mestrando em Saúde da Família. Universidade Federal do Ceará. E-mail: brenocavalcanteenfermagem@ gmail.com ORCID: https://orcid.org/0000-0002-4512-1944

4. Enfermeira. Mestranda em Saúde da Família. Universidade Federal do Ceará. E-mail: biancawdionisio@hotmail. com ORCID: https://orcid.org/0000-0002-0628-5807

5. Enfermeira. Mestranda em Saúde da Família. Universidade Federal do Ceará. E-mail: adriannavgomes@gmail.com ORCID: https://orcid.org/0000-0001-9522-9200 


\section{ABSTRACT}

The study aimed to analyze the scientific evidence dealing with occupational violence in health and the interfaces with work conditions and organization. This is an integrative review which takes in account original articles published in national and international journals. The descriptors "Violence at work", "Worker's Health" and "Basic Health Care" were crossed in the period from 2008 to 2018. The most prevalent type of occupational violence was physical, followed by psychological violence, patients were the main perpetrators, followed by their own co-workers. Investments in work conditions and organization reduce the chances of workplace violence. There is the need for the development of organizational strategies and policies in general for the protection of health professionals. Occupational violence is multi-causal with negative repercussions in the work context of the workers victims of abuse. Thus, the greater involvement of public managers and strategic planning actions can help with changes in this paradigm.

\section{RESUMEN}

El estudio tuvo como objetivo analizar las evidencias científicas que tratan acerca de la violencia ocupacional en la salud y las interfaces con las condiciones y organización laboral. Se trata de una revisión integrativa considerando artículos originales publicados en periódicos nacionales e internacionales. Fueron cruzados los descriptores "Violencia Laboral", "Salud del Trabajador" y "Atención Básica a la Salud", en el periodo de 2008 a 2018. El tipo de violencia ocupacional más prevalente fue la física, seguida de la violencia psicológica, los pacientes fueron los principales perpetradores seguidos de los propios colegas de trabajo. Inversiones en las condiciones y organización del trabajo reducen las chances de violencia en el local de trabajo. Hay necesidad de desarrollar estrategias organizacionales y políticas en general para la protección de los profesionales de salud. La violencia ocupacional es multicausal con reflejos negativos en el contexto laboral de los trabajadores violentados. De esa manera, el mayor involucramiento de gestores públicos y acciones de plan estratégico pueden auxiliar con los cambios de ese paradigma.

\section{INTRODUÇÃO}

A violência é compreendida como um problema social e de saúde pública mundial de difícil enfrentamento em razão de sua etiologia multicausal $^{1}$. Por ser inerente ao convivio social, às relações grupais e interpessoais, a violência também está projetada nas relações trabalhistas, campo propício para a prática de todas as formas de violência ${ }^{2}$.

A Organização Mundial da Saúde (OMS) define violência como o uso de força física ou poder, em ameaça ou na prática, contra si próprio, outra pessoa ou contra um grupo ou comunidade, que resulte ou possa resultar em sofrimento, morte, danos psicológicos, desenvolvimento prejudicado ou privação. A violência ocupacional é resultado da soma de diversos fatores, dentre os quais se destacam as condições de trabalho, a organização dos processos de trabalho e a interação trabalhador/agressor ${ }^{3}$. Esta é considerada um problema de saúde pública que resulta em danos na saúde do profissional, levando-o, por vezes, à dificuldade em reconhecer e enfrentar o fenômeno ${ }^{4}$.
De forma mais específica, a Organização Internacional do Trabalho (0IT) ${ }^{5}$ considera a expressão workplace violence - violência no local de trabalho - como qualquer ação, evento ou comportamento voluntário, em consequência dos quais uma pessoa é agredida, ameaçada ou sofre algum dano ou lesão, durante a realização de seu trabalho ou como resultado de suas atividades laborais; dessa forma, nesses contextos há os riscos ocupacionais.

Concebe-se como riscos ocupacionais quaisquer elementos inerentes às situações de trabalho que podem provocar desequilíbrio físico, mental e social, superando a lógica restrita relacionada às doenças ou acidentes ocupacionais. Dessa forma, rejeitase a ideia de que a violência ocupacional comporte fatores unicamente pessoais e passa-se a considerála como resultante de uma combinação de causas relativas às pessoas, ao entorno, ao ambiente físico e social do trabalho e às condições organizacionais e contratuais de emprego, bem como às formas de interação entre os próprios trabalhadores, entre os clientes e os trabalhadores e entre esses e empresários ${ }^{6}$. 
Atualmente, a violência ocupacional é considerada um fenômeno em avanço no mundo, em especial no que diz respeito ao setor da saúde, o qual é apontado como o campo mais suscetível de ocorrência ${ }^{7}$, uma vez que a prevalência da violência na área da saúde varia entre $17 \%$ a $94 \%$, e mais de $50 \%$ dos profissionais são afetados ${ }^{1}$.

Esse tipo de violência, potencialmente, acarreta absenteísmo, licenças, rotatividade ou mesmo mudança de profissão, devido ao adoecimento psíquico, como depressão, sintomas psicossomáticos, desânimo, além de conflitos nos relacionamentos entre colegas de trabalho ${ }^{1,8}$. Estudos internacionais que abordaram o fenômeno da violência ocupacional em serviços de saúde demonstraram preocupação com esses episódios ${ }^{9-11}$, fato também evidenciado em investigações brasileiras ${ }^{12-15}$, embora ainda se apresentem incipientes e em diversos contextos. É válido destacar que há violência ocupacional em todos os níveis de saúde no Brasil.

Contudo, os profissionais da Estratégia Saúde da Família (ESF) veem sendo alvos das comunidades nas quais estão inseridos ${ }^{16-18}$. Historicamente, a Atenção Básica à Saúde (ABS) é um serviço que funciona como porta de entrada preferencial para o sistema de saúde, conforme as necessidades e problemas dos usuários. Esta tem como pressuposto a oferta de atenção e cuidado longitudinal, para todas as condições, além de coordenar e integrar a Rede de Atenção à Saúde ${ }^{19}$.

A Política Nacional de Atenção Básica (PNAB) aposta na ESF enquanto ação prioritária para a expansão, consolidação e qualificação da ABS no Brasil $^{20}$, sobretudo por reconhecê-la como cenário onde os profissionais atuam diretamente com a comunidade e suas demandas sociofamiliares. Tal característica pode afetar não só os usuários, mas também os profissionais de saúde, tanto no acesso territorial como no desenvolvimento e planejamento de processos de trabalho. É possível, ainda, observar que situações de violência geram uma maior rotatividade dos profissionais, gerando descontinuidade nos processos de trabalho e enfraquecimento do vínculo entre usuário e profissional na ESF ${ }^{21}$.

Há alguns fatores que podem potencializar e predispor ocorrências de situações de violência no trabalho, estes são fatores ambientais e organizacionais ${ }^{22}$, dentre eles: trabalhar com usuários que possuem histórico de violência, trabalhar sozinho, ambientes mal iluminados e que possuem alta circulação de pessoas não identificadas, déficit de trabalhadores, ausência de treinamentos para identificar possíveis agressores, falta de segurança e regiões com altas taxas de criminalidade ${ }^{22}$.

$\mathrm{Na} A B S$, os aspectos referentes às regiões com altas taxas de criminalidade e com pouco fluxo de pessoas podem ser os fatores que merecem maior atenção, tendo em vista que as unidades das ESF têm como princípio básico a aproximação com a comunidade e o domicílio das pessoas. Dessa forma, entende-se que trabalhar nas comunidades em que a criminalidade é constante pode potencializar a chance de exposição dos profissionais da $A B S$ à violência laboral ${ }^{12}$.

Cabe mencionar, ante o exposto, que ancorar-se no aprofundamento sobre a violência ocupacional a partir da exploração de produções científicas, por meio da revisão integrativa, torna-se essencial. Com vistas a fomentar novas pesquisas e enriquecer a literatura na área, reduzindo as lacunas do conhecimento existentes, tendo como foco a melhoria da qualidade dos serviços e a proteção à saúde dos profissionais de saúde, em especial dos trabalhadores da ESF.

Assim, objetivou-se analisar as evidências científicas que tratam sobre violência ocupacional na Atenção Básica à Saúde e suas interfaces com as condições e a organização do trabalho.

\section{METODOLOGIA}

Trata-se de uma revisão integrativa, realizada de maio a junho de 2019, seguindo as etapas: definição da questão norteadora; estabelecimento das informações a serem investigadas nos estudos; análise dos estudos que integram a amostra; sintese dos resultados; e apresentação da revisão ${ }^{23}$.

Utilizou-se do acrônimo PICo para a formulação da pergunta de pesquisa: P - corresponde ao problema e é representado pelo trabalhador(a); I - é o fenômeno de interesse, caracterizado pela violência ocupacional; e Co - o contexto, que consiste na Atenção Básica. Assim, o estudo teve como questão norteadora: A quais tipos de violência no trabalho os profissionais estão expostos e quais são as interfaces com as condições e a organização do trabalho na ABS?

A sistematização da busca de dados iniciou-se pela procura de artigos publicados entre 2008 e 2018. Pontua-se que a abrangência de dez anos se deu devido à escassez da temática na literatura, 
portanto, decidiu-se expandir o período de publicação a fim de manter o rigor da revisão. A busca inicial foi feita por meio do levantamento das produções relacionadas à temática na Biblioteca Virtual em Saúde (BVS), na Base de Dados em Enfermagem (BDENF) e PubMed/MEDLINE. Na busca realizada, utilizou-se como estratégia os descritores: "Violência no Trabalho", "Saúde do Trabalhador" e "Atenção Básica à Saúde", combinados com o operador booleano and, bem como os termos MeSH: "Workplace Violence", "Occupational Health Primary" e "Health Care", também combinados com o operador and.

Estabeleceram-se como critérios de inclusão: estudos originais, sistemáticos, disponíveis na íntegra, publicados entre 2008 e 2018 e nos idiomas português e inglês. Foram excluídas as produções duplicadas, bem como estudos de revisão e aqueles que não abordassem temática relevante a alcance do objetivo da pesquisa. 0 resultado final da busca resultou em 13 artigos científicos.

\section{RESULTADOS}

A partir da análise dos 13 artigos selecionados, nota-se que os anos de 2015 e 2016 sobressaíram-se no que diz respeito ao maior número de publicação, seis. 0s achados sobre a origem das pesquisas foram equilibrados, seis internacionais e sete nacionais, mas cabe sublinhar que, mesmo com a escassez de pesquisas voltadas para essa área, o Brasil se destacou.

A fim de ensejar a caracterização dos estudos, elaborou-se o Quadro 1, que visa apresentá-los quanto ao título do artigo, objetivo, tipo de estudo, principais resultados e ano de publicação.

Quadro 1. Caracterização das produções científicas acerca da violência no trabalho na Atenção Básica à Saúde, no período de 2008 a 2018.

\begin{tabular}{|c|c|c|c|c|}
\hline Titulo & Objetivo & Tipo de estudo & Principais resultados & Ano \\
\hline $\begin{array}{l}\text { A violência e os } \\
\text { profissionais da } \\
\text { saúde na Atenção } \\
\text { Primária }\end{array}$ & $\begin{array}{c}\text { Conhecer as situações } \\
\text { em que se dão as } \\
\text { agressões aos } \\
\text { profissionais de saúde } \\
\text { na Atenção Primária } \\
\text { em saúde }\end{array}$ & $\begin{array}{c}\text { Estudo } \\
\text { qualitativo }\end{array}$ & $\begin{array}{l}\text { Os fatores associados ao risco } \\
\text { de exposição à violência } \\
\text { e suas implicações pelos } \\
\text { profissionais poderiam ser } \\
\text { amenizados por meio de } \\
\text { educação permanente e } \\
\text { autodesenvolvimento }\end{array}$ & 2008 \\
\hline $\begin{array}{l}\text { Percepção do risco } \\
\text { no trabalho em } \\
\text { Saúde da Família: } \\
\text { estudo com } \\
\text { trabalhadores no sul } \\
\text { do Brasil }\end{array}$ & $\begin{array}{l}\text { Identificar a } \\
\text { percepção dos } \\
\text { trabalhadores da ESF } \\
\text { a respeito dos riscos a } \\
\text { que se expõem no seu } \\
\text { processo de trabalho }\end{array}$ & $\begin{array}{c}\text { Estudo } \\
\text { transversal }\end{array}$ & $\begin{array}{l}\text { A percepção de risco foi } \\
\text { apreendida como um conjunto } \\
\text { de significados construídos } \\
\text { individual e coletivamente } \\
\text { a partir dos trabalhadores } \\
\text { que produzem e reproduzem } \\
\text { formas semelhantes e diversas } \\
\text { ao mesmo tempo }\end{array}$ & 2009 \\
\hline $\begin{array}{l}\text { Violência no } \\
\text { trabalho em saúde: } \\
\text { análise em Unidades } \\
\text { Básicas de Saúde } \\
\text { de Belo Horizonte, } \\
\text { Minas Gerais }\end{array}$ & $\begin{array}{l}\text { Investigar e } \\
\text { compreender a } \\
\text { violência vivenciada } \\
\text { em unidades básicas } \\
\text { de saúde (UBS) da } \\
\text { perspectiva dos } \\
\text { processos de trabalho } \\
\text { em saúde }\end{array}$ & $\begin{array}{c}\text { Estudo } \\
\text { qualitativo }\end{array}$ & $\begin{array}{l}\text { 0 enfrentamento da violência } \\
\text { implica na formulação de } \\
\text { políticas gerais e implantação } \\
\text { de ações voltadas para o } \\
\text { processo de trabalho nas UBS } \\
\text { e no sistema de saúde como } \\
\text { um todo }\end{array}$ & 2011 \\
\hline
\end{tabular}




\begin{tabular}{|c|c|c|c|c|}
\hline $\begin{array}{l}\text { Safety measures to } \\
\text { preve nt workplace } \\
\text { violence in } \\
\text { emergency } \\
\text { p rimary care } \\
\text { centres- } \\
\text { a cross-sectional } \\
\text { study }\end{array}$ & $\begin{array}{c}\text { Investigar até que } \\
\text { ponto os clínicos } \\
\text { gerais trabalham } \\
\text { sozinhos nos Centros } \\
\text { de Atendimento } \\
\text { Primário de } \\
\text { Emergências (EPCCs) } \\
\text { na Noruega e estimar a } \\
\text { prevalência de outras } \\
\text { medidas pre ventivas } \\
\text { contra a violência no } \\
\text { local de trabalho }\end{array}$ & $\begin{array}{c}\text { Estudo } \\
\text { quantitativo }\end{array}$ & $\begin{array}{l}\text { Há diferenças consideráveis } \\
\text { entre as EPCCs norueguesas, } \\
\text { em relação às medidas } \\
\text { preventivas aplicadas, e uma } \\
\text { maior prevalência de medidas } \\
\text { de proteção nas EPCCs com } \\
\text { funcionários } 24 \text { horas por dia. }\end{array}$ & 2013 \\
\hline $\begin{array}{l}\text { Dealing with } \\
\text { workplace violence } \\
\text { in emergency } \\
\text { primary heal th care: } \\
\text { a focus group study }\end{array}$ & $\begin{array}{c}\text { Explorar como o } \\
\text { pessoal lida com as } \\
\text { ameaças e violência } \\
\text { dos visitantes ou } \\
\text { pacientes, com ênfase } \\
\text { em como os fatores } \\
\text { organizacionais } \\
\text { interferem nos } \\
\text { incidentes }\end{array}$ & $\begin{array}{c}\text { Estudo } \\
\text { qualitativo }\end{array}$ & $\begin{array}{l}\text { Existe um potencial para } \\
\text { o desenvolvimento de } \\
\text { estratégias organizacionais } \\
\text { para proteger o pessoal } \\
\text { da ABS que corre risco de } \\
\text { violência no local de trabalho }\end{array}$ & 2015 \\
\hline $\begin{array}{l}\text { Does workplace } \\
\text { violenc e exist in } \\
\text { primary health care? } \\
\text { Evidence from Serbia }\end{array}$ & $\begin{array}{c}\text { Estimar a prevalência } \\
\text { de violência no } \\
\text { local de trabalho e } \\
\text { identificar } \\
\text { potenciais preditores } \\
\text { de violência no } \\
\text { trabalho em centros de } \\
\text { cuidados primários } \\
\text { à saúde }\end{array}$ & $\begin{array}{c}\text { Estudo } \\
\text { transversal }\end{array}$ & $\begin{array}{l}\text { Mais da metade dos } \\
\text { funcionários foram expostos a } \\
\text { diferentes tipos de violência } \\
\text { no local de trabalho. Há } \\
\text { necessidade de intervenções } \\
\text { para proteger os profissionais } \\
\text { de saúde e } \\
\text { proporcionar ambientes } \\
\text { de trabalho mais seguros }\end{array}$ & 2015 \\
\hline $\begin{array}{l}\text { Validade aparente } \\
\text { de um questionário } \\
\text { para avaliação } \\
\text { da violência no } \\
\text { trabalho }\end{array}$ & $\begin{array}{c}\text { Elaborar um } \\
\text { questionário para } \\
\text { avaliação da violência } \\
\text { no trabalho, sofrida } \\
\text { ou testemunhada } \\
\text { por trabalhadores de } \\
\text { enfermagem, e avaliar } \\
\text { sua validade aparente }\end{array}$ & $\begin{array}{l}\text { Estudo } \\
\text { metodológico }\end{array}$ & $\begin{array}{l}\text { Espera-se que o questionário } \\
\text { possa representar, aos } \\
\text { interessados, mais uma } \\
\text { possibilidade de mensuração } \\
\text { da ocorrência de violência } \\
\text { no ambiente de trabalho na } \\
\text { enfermagem e na saúde }\end{array}$ & 2015 \\
\hline $\begin{array}{l}\text { Aggressions towards } \\
\text { Primary Health Care } \\
\text { Workers in Madrid, } \\
\text { Spain, } 2011-2012\end{array}$ & $\begin{array}{l}\text { Caracterizar } \\
\text { agressões na Atenção } \\
\text { Primária em Madri }\end{array}$ & $\begin{array}{c}\text { Estudo } \\
\text { transversal } \\
\text { multicêntrico }\end{array}$ & $\begin{array}{l}\text { O risco de agressão é } \\
\text { maior nos profissionais de } \\
\text { saúde, principalmente nos } \\
\text { médicos. Houve diferenças } \\
\text { significativas por sexo e } \\
\text { idade, tanto no perfil do } \\
\text { agressor quanto na vítima }\end{array}$ & 2016 \\
\hline
\end{tabular}




\begin{tabular}{|c|c|c|c|c|}
\hline $\begin{array}{l}\text { Evaluation of the } \\
\text { users violence in } \\
\text { primary health care: } \\
\text { Adaptation of an } \\
\text { instrument. }\end{array}$ & $\begin{array}{c}\text { Estudar a prevalência } \\
\text { de violência } \\
\text { no trabalho em } \\
\text { profissionais da } \\
\text { Atenção Primária } \\
\text { à saúde (APS), } \\
\text { adaptando a Escala } \\
\text { de Comportamento } \\
\text { Agressivo do } \\
\text { Trabalhador da } \\
\text { Saúde (HABS-U) }\end{array}$ & Estudo misto & $\begin{array}{l}\text { A distribuição da violência } \\
\text { dos usuários não é homogênea } \\
\text { entre os diferentes grupos } \\
\text { profissionais da APS. A } \\
\text { adaptação da escala pode ser } \\
\text { útil para detectar a violência } \\
\text { do usuário, bem como avaliar } \\
\text { a eficácia dos programas de } \\
\text { intervenção }\end{array}$ & 2016 \\
\hline $\begin{array}{l}\text { Violência no } \\
\text { trabalho da } \\
\text { Enfermagem: } \\
\text { um olhar às } \\
\text { consequências }\end{array}$ & $\begin{array}{l}\text { Refletir acerca das } \\
\text { consequências da } \\
\text { violência no trabalho } \\
\text { experienciada por } \\
\text { profissionais de } \\
\text { enfermagem }\end{array}$ & Estudo reflexivo & $\begin{array}{c}\text { Aponta-se para o } \\
\text { potencial nocivo e oneroso } \\
\text { deste fenômeno, por ser capaz } \\
\text { de ocasionar sofrimento, } \\
\text { adoecimento, afastamentos do } \\
\text { trabalho e até a morte }\end{array}$ & 2016 \\
\hline $\begin{array}{l}\text { Estratégias } \\
\text { utilizadas pela } \\
\text { enfermagem } \\
\text { em situações de } \\
\text { violência no } \\
\text { trabalho em } \\
\text { hemodiálise }\end{array}$ & $\begin{array}{l}\text { Identificar as } \\
\text { estratégias utilizadas } \\
\text { pelos trabalhadores } \\
\text { de enfermagem } \\
\text { de um serviço de } \\
\text { hemodiálise, em } \\
\text { situações de violência } \\
\text { perpetrada por } \\
\text { pacientes durante a } \\
\text { assistência. }\end{array}$ & $\begin{array}{c}\text { Estudo } \\
\text { qualitativo }\end{array}$ & $\begin{array}{l}\text { Evidencia-se a necessidade } \\
\text { de mobilização coletiva } \\
\text { dos trabalhadores e, } \\
\text { principalmente, da instituição } \\
\text { como mediadora, na busca } \\
\text { pela prevenção e não } \\
\text { propagação da violência } \\
\text { no ambiente de trabalho }\end{array}$ & 2011 \\
\hline $\begin{array}{l}\text { A violência contra } \\
\text { os profissionais da } \\
\text { enfermagem no setor } \\
\text { de acolhimento } \\
\text { com classificação de } \\
\text { risco }\end{array}$ & $\begin{array}{c}\text { Conhecer os tipos } \\
\text { de violência e os } \\
\text { fatores que contribuem } \\
\text { para os atos violentos } \\
\text { sofridos pela equipe } \\
\text { de enfermagem no } \\
\text { acolhimento com } \\
\text { classificação de } \\
\text { risco (ACCR) }\end{array}$ & $\begin{array}{l}\text { Estudo } \\
\text { descritivo de } \\
\text { abordagem } \\
\text { qualitativa }\end{array}$ & $\begin{array}{l}\text { É necessário trabalhar a } \\
\text { educação continuada com } \\
\text { profissionais de saúde } \\
\text { e atividades educativas } \\
\text { com usuários do ACCR, } \\
\text { para promover relações } \\
\text { harmoniosas entre } \\
\text { profissionais e usuários }\end{array}$ & 2018 \\
\hline $\begin{array}{l}\text { Violência física } \\
\text { e psicológica } \\
\text { perpetrada no } \\
\text { trabalho em saúde }\end{array}$ & $\begin{array}{l}\text { Analisar a presença } \\
\text { da violência física } \\
\text { e psicológica entre } \\
\text { trabalhadores da } \\
\text { saúde, identificar } \\
\text { seus perpetradores e } \\
\text { compreender a origem } \\
\text { das agressões }\end{array}$ & $\begin{array}{l}\text { Estudo de } \\
\text { abordagem mista }\end{array}$ & $\begin{array}{l}\text { A violência psicológica foi } \\
\text { prevalente; mulheres e } \\
\text { técnicos de enfermagem foram } \\
\text { os mais expostos e pacientes } \\
\text { os principais perpetradores. } \\
\text { São necessárias medidas } \\
\text { de contenção e prevenção } \\
\text { e investimentos sobre as } \\
\text { condições e a organização do } \\
\text { trabalho no hospital }\end{array}$ & 2018 \\
\hline
\end{tabular}

Fonte: Dados da pesquisa.

Em relação às publicações internacionais, países como Noruega e Espanha foram evidenciados nas buscas, e, em âmbito brasileiro, as regiões Sudeste e Sul se sobressaíram. No tocante ao idioma, observou-se que 
quatro dos artigos foram publicados em inglês, dois em espanhol e sete em português.

\section{DISCUSSÃO}

0 estudo realizado com profissionais de saúde da Atenção Primária em Madri, na Espanha, apresentou que, dentre as 1.157 agressões notificadas, 53\% foram sofridas por médicos. Em $4,7 \%$ dos casos houve agressão física. 0 principal motivo foi devido à insatisfação com o atendimento recebido $(36,1 \%)$. Outra pesquisa pontua que profissionais que não são da saúde apresentaram menor risco de agressão física. A agressão foi cometida por homens em $56,8 \%$ dos casos e na faixa etária entre 31-40 anos em $26,8 \%$. A mulher foi o sexo mais acometido pelas agressões, em $84 \%$ dos casos, com idades entre 45 e $60 \operatorname{anos}^{24}$.

No estudo ${ }^{17}$ realizado em Belgrado, na Sérvia, com 1.526 profissionais médicos e não médicos, $803(52,6 \%)$ sofreram violência no trabalho, dos quais $147(18,3 \%)$ foram expostos à violência física, não havendo diferença significativa na exposição à violência no local de trabalho de acordo com sexo, idade, estado civil, nível de escolaridade ou anos de experiência do profissional. No entanto, a prevalência no trabalho foi significativamente maior entre os funcionários que trabalhavam no turno noturno e que interagiam diretamente com os pacientes $(P<0,001)$.

Nesse mesmo estudo, percebeu-se a violência mais prevalente entre os funcionários que trabalhavam com crianças em idade pré-escolar. Entre os principais tipos de violência acometida, a verbal foi a mais prevalente e um terço dos profissionais entrevistados experimentaram dois tipos de violência: a verbal e o assédio moral ${ }^{17}$.

Na pesquisa ${ }^{25}$ desenvolvida na Noruega, a violência no trabalho destacou-se como um dos principais problemas e, apesar do alto risco de exposição, o conhecimento sobre as medidas preventivas aplicadas eram limitados. Como exemplos de medidas de segurança mais comuns, foram citadas as fechaduras automáticas $(p<0,001)$, disposição dos móveis na sala de consulta $(p=0,014)$, a possibilidade de trazer uma pessoa extra durante chamadas de emergência ou visitas domiciliares quando necessário, por razões de segurança $(p=0,014)$, e organização de treinamento sobre violência $(p<0,001)$.

A literatura revela os riscos que os trabalhadores da ESF no Rio Grande do Sul estão expostos, destacando algumas categorias importantes: acidente de trabalho típico (ocorrendo no ambiente de trabalho), doença relacionada ao trabalho, exaustão emocional, falta de habilidade para resolver problemas e violência física e moral. Dos 48 trabalhadores entrevistados, 23 mencionaram a percepção de risco para "violência física e moral", quando afirmaram que a violência parece estar diretamente ligada ao objeto/sujeito da ação, ou seja, o elemento condicionador centrado nas características sociocomportamentais dos grupos nas comunidades relacionadas ${ }^{26}$.

Uma nova perspectiva desse cenário foi proposta em uma pesquisa ${ }^{27}$ que visou conhecer as situações em que se dão as agressões aos profissionais de saúde, destacando-se sete diferentes categorias: o processo de trabalho na Atenção Primária; as necessidades de saúde da população; o risco de exposição à agressão; o agressor; os tipos de agressão sofridos; o papel da gestão e do profissional da saúde no contexto da Atenção Primária. Evidenciaram-se, portanto, alguns fatores associados ao risco de exposição à violência e suas implicações, contribuindo com informações e conhecimentos que podem atenuar esses eventos ${ }^{27}$.

Nesse sentido, foram citadas também quatro principais formas de minimizar a violência sofrida pelos profissionais: (1) uso de alarme sonoro com capacidade de convocar alguém em uma situação ameaçadora; (2) reunir o máximo de informação sobre o paciente, para caso necessário alertar os colegas de trabalho e acionar a polícia quando a consulta tornar-se complicada; (3) resolver o descompasso entre as expectativas do paciente e o serviço oferecido, melhorando as condições e organização do trabalho; e (4) resposta de apoio do gerente participantes descreveram o papel fundamental do gerente em fornecer suporte no acompanhamento de episódios ${ }^{25}$.

Ao investigar e compreender a violência vivenciada em Centros de Saúde da Família (CSF) em Minas Gerais, da perspectiva dos processos de trabalho em saúde, evidenciou-se a necessidade de fortalecer não só a humanização e a gestão do trabalho em saúde, mas também a formação dos profissionais, atreladas às melhorias nas condições e no ambiente de trabalho e, consequentemente, na prestação dos serviços de saúde ${ }^{15}$.

0 estudo supracitado identificou como eixos relevantes para o tema: as estratégias individuais diante da violência; respostas institucionais e mecanismos de apoio e suporte; consequências e impactos da violência; e ações preventivas. Essas 
ações preventivas foram elencadas como: conduta pessoal ou a forma de contato com o paciente com uma abordagem mais cordial e com disponibilidade, estratégias preventivas, o programa HumanizaSUS, o vínculo com a comunidade e a medida institucional considerada de maior impacto, com a atuação da Guarda Municipal nos centros de saúde ${ }^{13}$.

A respeito dos tipos de violências no trabalho que os profissionais da ABS estão expostos, as pesquisam evidenciam que mais da metade dos funcionários foram expostos a diferentes tipos de violência, desde violência verbal, psicológica à agressão física, sendo praticadas, em especial, por pacientes/clientes, mas também propagadas por colegas de trabalho. As implicações da violência laboral se apresentam de modo direto e indireto nas condições e na organização do trabalho desses profissionais, ocasionando sofrimento, adoecimento, afastamentos do trabalho e até a morte.

Tanto nos estudos internacionais quanto nos nacionais a violência ocupacional se destaca como problema de saúde pública. Notou-se que esta pouco tem sido identificada, mensurada e prevenida; em contraponto, muitas vezes, vem sendo naturalizada no cotidiano dos serviços de saúde ${ }^{28}$. Seja por sua etiologia, que é multicausal e com elevadas repercussões não só no contexto laboral dos trabalhadores violentados, seja no contexto pessoal, especificamente envolvendo a autoestima, vida familiar e relações pessoais; por isso, esse fenômeno merece a atenção especial dos gestores públicos e profissionais de saúde. A partir dessas premissas, torna-se crucial o envolvimento dos trabalhadores, gestores, universidades e representantes políticos em reconhecerem as causas e as consequências da violência ocupacional, elaborando estratégias pertinentes para a sua superação e prevenção.

\section{CONCLUSÃO}

A partir de tais resultados, enfatiza-se que o estudo possa vir a contribuir com uma visão mais crítica no que diz respeito à análise do fenômeno da violência ocupacional em profissionais de saúde, com foco na Atenção Básica, já que se considera, após a análise, que há a necessidade de realizar mais pesquisas que correlacionem o tema e a ABS, em específico com os profissionais que compõem a ESF, pois há lacunas no conhecimento sobre as violências ocupacionais neste cenário. Ainda que mantendo o rigor exigido na revisão integrativa e ampliando a busca em bases nacionais e internacionais, localizaram-se poucas pesquisas sobre a temática. Fato que reverbera na compreensão da necessidade de implementar e realizar pesquisas que investiguem e correlacionem o tema.

Desse modo, se há informações pertinentes e relevantes sobre o tema, pode-se refletir criticamente, criar estratégias que visem prevenir os atos violentos - realizados pelos usuários ou mesmo colegas de trabalho -, ou seja, ao caracterizar os tipos de violência que os profissionais são acometidos, pode-se elaborar condutas mais eficientes e efetivas diante dos casos, sejam os mais leves e/ou graves, e, por fim, suprimindo a escassez de estratégias para a abordagem das violências ocupacionais.

Consiste em uma limitação deste estudo a não inclusão de outras fontes de literatura científica. Outro ponto a ser considerado diz respeito à não utilização de termos não controlados e outros idiomas.

\section{CONTRIBUIÇÃO DOS AUTORES}

Anny Caroline dos Santos Olímpio contribuiu no delineamento do estudo, interpretação e análise dos dados, estruturação crítica da redação científica e revisão da versão final do manuscrito. João Breno Cavalcante participou da produção e delineamento do estudo. Adriana Vasconcelos Gomes e Bianca Waylla Ribeiro Dionisio contribuíram na interpretação e análise dos resultados, estruturação crítica da redação científica e revisão final do manuscrito. Roberta Cavalcante Muniz Lira contribuiu na estruturação crítica da redação científica, leitura e revisão final do manuscrito.

\section{REFERÊNCIAS}

1. Neto EMN, Araújo TM, Sousa CC, Souza Soares JF, Lua I. Violência no trabalho em saúde nos serviços de média complexidade. Rev saúde colet UEFS. 2018; 8(1):62-69. doi: https://doi.org/10.13102/ rscdauefs.v8i1.2115

2. Ramos RWC. Uma análise do assédio moral na relação entre clube e atleta profissional de futebol [monografia]. Guanambi: Centro Universitário Faculdade Guanambi; 2021. $25 \mathrm{f}$.

3. Krug EG, Dahlberg LL, Mercy JA, Zwi AB, Lozano $R$. Informe mundial sobre laviolencia y lasalud. Geneva: 0MS; 2002. 
4. Cordenuzzi OCP. Violência no trabalho da enfermagem em um serviço de hemodiálise [dissertação]. Santa Maria: Universidade Federal de Santa Maria; 2011. 101 p.

5. Organização Internacional do Trabalho; International Council of Nurses; Organização Mundial da Saúde. Workplace violence in the health sector - country case studies research instruments. Researchprotocol. Genebra: 0IT; 2003.

6. Nascimento CL et al. Violência na Estratégia de Saúde da Família: riscos para a saúde dos trabalhadores e ao atendimento. Rev enferm UERJ. $2020 ; 28: 45789$.

7. Rocha MAS, Silva ACA, Assis MA. A prática da violência voltada aos profissionais da enfermagem. Diálogos int. 2018; 7(2):100-108.

8. Almeida NR, Bezerra Filho JG, Marques LA. Análise da produção científica sobre a violência no trabalho em serviços hospitalares. Rev bras med trab. 2017; 15(1):101-112. doi: http://dx.doi.org/10.12957/ reuerj.2020.45789

9. Escribano RB, Beneit J, Garcia JL. Violence in the workplace: some critical issues looking at the health sector. Heliyon. 2019; 5(3):e01283. doi: http:// dx.doi.org/10.1016/j.heliyon.2019.e01283

10. Pien LC, Cheng Y, Cheng WJ. Internal workplace violence from colleagues is more strongly associated with poor health outcomes in nurses than violence from patients and families. J adv nurs. 2019; 75(4):793-800. http://dx.doi.org/10.1111/jan.13887

11. Cheung T, Yip PSF. Workplace violence towards nurses in Hong Kong: prevalence and correlates. BMC public health. $2017 ; 17(1): 196$.

12. Sturbelle ICS. Violência no trabalho em unidades de saúde da família e as suas interfaces com as condições e a organização do trabalho [dissertação]. Porto Alegre: Universidade Federal do Rio Grande do Sul; 2018. 109 p.

13. Dal Pai D, Sturbelle ICS, Santos CD, Tavares JP, Lautert L. Violência física e psicológica perpetrada no trabalho em saúde. Texto contexto enferm. 2018; 27(1):e2420016.

14. Pedro DRC, Silva GKTD, Lopes APAT, Oliveira JLCD, Tonini NS. Violência ocupacional na equipe de enfermagem: análise à luz do conhecimento produzido. Saúde debate. 2017; 41:618-629.

15. Batista CB, Souza Campos A, Carmo Reis J, Schall VT. Violência no trabalho em saúde: análise em unidades básicas de saúde de Belo Horizonte, Minas Gerais. Trab. educ saúde. 2011; 9(2):295-317.
16. Lima TF. Exposição à violência comunitária durante o trabalho e seus efeitos na prática profissional na estratégia saúde da família: um estudo de cortetransversal no município de São Paulo [dissertação]. São Paulo: Universidade de São Paulo; 2017. 118 p.

17. Fisekovic MB, Trajkovic GZ, Bjegovic-mikanovic VM, Terzic-supic ZJ. Does workplace violence exist in primary health care? Evidence from Serbia. Eur J Public Health. 2015; 25(4): 693-98.

18. Brasil. Projeto Promoção da Saúde. Declaração de Alma-Ata, Carta de Ottawa, Declaração de Adelaide, Declaração de Sundswall, Declaração de Santa Fé de Bogotá, Declaração de Jacarta, Rede de Megapaíses. Brasília (DF): Ministério da Saúde; 2001.

19. Starfield B. Atenção primária: equilíbrio entre necessidades de saúde, serviços e tecnologia. Brasília (DF): Unesco; 2002.

20. Brasil. Política Nacional de Atenção Básica. Brasília (DF): Ministério da Saúde; 2017.

21. Silva ATC, Peres MFT, Lopes CS, Schraiber LB, Susser E, Menezes PR. Violence at work and depressives ymptoms in primary health care teams: a cross-sectional study in Brazil. Soc Psychiatry Epidemiol. 2015; 50:1347-55.

22. Occupational Safety and Health Administration. Guidelines for preventing workplace violence for health care social service workers. In Guidelines for preventing workplace violence for health care social service workers. OSHA; 2004.

23. Doricci GC; Guanaes-Lorenzi C. Revisão integrativa sobre cogestão no contexto da Política Nacional de Humanização. Ciênc saúde colet. 2021; 26:2949-59.

24. Rincón-Del TT, Villanueva-Guerra A, RodríguezBarrientos R, Polentinos-Castro E, Torijano-Castillo MJ, GregorioEscrivá BDR, et al. Aggressions towards primary health care workers in Madrid, Spain, 20112012. Rev española de salud pública. 2016; 90:e1e12.

25. Morken T, Johansen IH, Alsaker K. Dealing with workplace violence in emergency primary health care: a focus group study. BMC family practice. $2015 ; 16(1): 51$.

26. Cezar-Vaz MR, Souza Soares JF, Figueiredo PP, Azambuja EP, Sant'Anna CF, Costa VZ. Percepção do risco no trabalho em saúde da família: estudo com trabalhadores no sul do Brasil. Rev Latino-Am Enferm. 2009; 17(6):961-67.

27. Kaiser DE, Bianchi F. A violência e os profissionais da saúde na atenção primária. Revista gaúcha de enfermagem. Porto Alegre. 2008; 29(3):362-366. 
28. Benicio LFS, Barros JPP. Estratégia Saúde da

Família e violência urbana: abordagens e práticas sociais em questão. Sanare (Sanare, Online). 2017; $16(1): 102-112$. 